\title{
CORRECTION
}

\section{Publisher Correction: Integrating digital pathology into clinical practice}

Matthew G. Hanna (iD, Orly Ardon (iD, Victor E. Reuter, Christine England, David S. Klimstra and Meera R. Hameed (iD)

(C) The Author(s), under exclusive licence to United States \& Canadian Academy of Pathology 2021

Modern Pathology (2022) 35:287; https://doi.org/10.1038/s41379-021-00948-x

Correction to: Modern Pathology https://doi.org/10.1038/s41379021-00929-0, published online 01 October 2021
The original version of this article unfortunately contained a mistake. Due to a typesetting error the running title appeared in the title of the article. We sincerely apologize for the mistake. The original article has been corrected. 